\title{
Literatura artística nas bibliotecas dos colégios jesuíticos de Lisboa Santo Antão e São Roque*
}

\author{
Art Literature in the libraries \\ of the Jesuit colleges of Lisbon
}

Santo Antão and São Roque

\author{
MARÍLIA DE AZAMBUJA RIBEIRO** \\ Departamento de História \\ Universidade Federal de Pernambuco \\ Recife (PE) \\ Brasil
}

RESUMO O artigo trata da presença de livros de "literatura artística" nas bibliotecas da Companhia de Jesus em Lisboa, compreendendo na "literatura artística" somente os testemunhos histórico-literários que dizem respeito à vida e à obra de pintores, escultores e arquitetos e aquelas obras de caráter teórico-conceitual que expõem de modo sistemático uma determinada arte, disciplina artística ou matéria particular; em outras palavras, a tratadística.

Palavras-chave literatura artística, Companhia de Jesus, Lisboa

ABSTRACT The article addresses the presence of "art literature" books in Society of Jesus' libraries in Lisbon, regarding as "art literature" only historical-literary testimonials concerning the lives of painters, sculptors and

* Artigo recebido em: 22/04/2012. Aprovado em: 17/10/2012.

** Contato: ribeiromarilia@hotmail.com. 
architects and those theorical-conceptual writings that systematically outlines a certain art, artistic subject or particular matter, i.e. the body of serious.

Keywords art literature, Society of Jesus, Lisbon

\section{Introdução}

Desde seus primórdios a historiografia portuguesa de cunho acadêmico teve ciência da centralidade que instituições de ensino da Companhia de Jesus tiveram no contexto do reino português e suas possessões ultramarinas ao longo dos primeiros séculos da Idade Moderna. Todavia, só mais recentemente o papel desses centros de ensino como lugares de difusão de saberes tem sido resgatado, com a superação de um paradigma historiográfico que, como bem demonstra José Eduardo Franco, tinha suas raízes fincadas no antijesuitismo pombalino e projetava sobre os inacianos e suas escolas a culpa pelo "obscurantismo" da Lusitânia pré-iluminista. ${ }^{1}$

Paradoxalmente, não foi no campo dos studia humanitatis, como se poderia esperar, que se deu esse resgate, mas sim pelas mãos dos historiadores da ciência. Foram eles que, nas últimas décadas, passaram a atentar para a importância das universidades e colégios jesuíticos, em particular do Colégio de Santo Antão em Lisboa, na transmissão e difusão dos conhecimentos técnicos e científicos em Portugal. ${ }^{2}$ A maioria desses estudiosos, porém, tem seu foco voltado para a circulação de conhecimentos cosmológicos, astronômicos e geográficos, de modo que ainda faltam estudos mais aprofundados sobre os demais ensinamentos então agrupados no contexto da disciplina Matemática, como a Astrologia, a Óptica, a Perspectiva, a Arquitetura, a Cenografia etc. ${ }^{3}$

De resto, parte conspícua desses estudos se debruçou sobre a tratadística, ou seja, sobre os escritos acerca dessas matérias produzidos em Portugal. Nesse sentido, a história da arte e a história da ciência têm

1 FRANCO, José Eduardo. O mito dos Jesuítas: em Portugal, no Brasil e no Oriente (séculos XVI-XIX). Lisboa: Gradiva, 2007.

2 Ver: ALBUQUERQUE, Luís de. A 'aula de esfera' do Colégio de Santo Antão no século XVII. Anais da Academia Portuguesa de História, $2^{a}$ série, v.21, p.337-391, 1972; BALDINI, Ugo. L'insegnamento della matematica nel Collegio di S. Antão a Lisbona, 1590-1640. In: A Companhia de Jesus e a missionação no Oriente. Lisboa: Brotéria e Fundação Oriente, 2000, p.275-310; SARAIVA, Luís; LEITÃO, Henrique. The practice of mathematics in Portugal. Coimbra: Acta Universitatis Conimbrigensis, 2004 (Papers from the International Meeting organized by the Portuguese Mathematical Society, Óbidos, 16-18 November, 2000); CAROLINO, Luís Miguel; LEITẢO, Henrique. Natural philosophy and mathematics in portuguese universities, 1550-1650. In: FEINGOLD, Mordechai; BROTÓNS, Victor Navarro. (eds.). Universities and science in Early Modern Period. Dordrecht: Springer, 2006, p.153-168; LEITÃO, Henrique. A ciência na aula da esfera do Colégio de Santo Antão (1590-1759). Lisboa: Comissariado Geral das Comemorações do V Centenário do Nascimento de S. Francisco Xavier, 2007.

3 Fazem exceção alguns poucos estudos sobre a obra de Inácio Vieira: COELHO, João Paulo C. M. Inácio Vieira: optics and perspective as instruments towards a sensitive space. Nexus Network Jornal, v.13, n.2, p.315-335, jul. 2011; LEITAO, Henrique; MELLO, Magno. A pintura barroca e a cultura matemática dos Jesuítas: o tractado de prospectiva de Inácio Vieira, S. J. (1715). Revista de História de Arte, v.1, p.95-142, 2005. 
nos últimos anos compartilhado desse interesse por manuscritos inéditos, sua edição e o estudo dos mesmos, assim como pelo estudo de tratados publicados por autores portugueses ao longo da Idade Moderna.

Outra tipologia de estudos dedica-se à análise da recepção e da circulação de livros e escritos de autores portugueses e estrangeiros no contexto luso. É seguindo esse viés que, nesta sede, nos propomos a investigar a presença de "literatura artística" nas bibliotecas da Companhia de Jesus de Portugal e seu ultramar.

Não entendendo aqui a expressão "literatura artística" no sentido mais amplo: o de todo livro cujo conteúdo poderia ser utilizado pelo artista na realização de sua obra. Tal acepção significaria abranger uma grande variedade de gêneros, desde textos de caráter religioso, literatura histórica, mitografias etc. que poderiam fornecer informações sobre o tema a ser representado, até qualquer obra que possuísse uma ou mais gravuras que pudessem constituir-se como fonte iconográfica para o artista, de catecismos ilustrados a livros de emblemática ou iconologia.

Utilizaremos "literatura artística" no sentido mais restrito adotado por Schlosser, ${ }^{4}$ ou seja, compreendendo somente os testemunhos históricoliterários que dizem respeito à vida e à obra de pintores, escultores e arquitetos e aquelas obras de caráter teórico-conceitual que expõem de modo sistemático uma determinada arte, disciplina artística ou matéria particular; em outras palavras, a tratadística.

Para tanto, analisamos os catálogos dos livros das duas principais bibliotecas jesuíticas de Lisboa: a do Colégio de Santo Antão ${ }^{5}$ e a do Colégio de São Roque, ${ }^{6}$ hoje conservados na Biblioteca da Ajuda.

\section{Fontes da Antiguidade Clássica}

É amplamente reconhecida a importância dada aos conteúdos clássicos no contexto dos programas de estudo das escolas e universidades jesuíticas, tanto no que diz respeito ao ensino de retórica e humanidades, quanto naquele de filosofia natural.

Dentre os livros das bibliotecas lisboetas estudadas, encontramos pelo menos quatro obras da tradição clássica que serviram como importante

\footnotetext{
SCHLOSSER, Magnino. La letteratura artística. Firenze: La Nuova Itália Editrice, 1964.

5 Index librorum Bibliothecae Collegii Ulyssiponensis Divi Antonii Magni Societatis lesu. Anno MDCCXXXXV, Ms. 51-XI-44: copiado, em 1745, de outro anterior, segundo esclarece uma nota lançada ao alto, numa das primeiras folhas: "O Índice antigo, do qual este foi trasladado, se conserva no Cub. do P.e Reitor".

6 Catalogus authorum qui sunt in D. Rochi Biblioteca (A-Z), Ms. 51-XI-38. Segundo Pereira Gomes, foi escrito por volta de 1710. Na Biblioteca da Ajuda, segundo o mesmo autor, existiam outros dois catálogos da livraria de São Roque. O mais antigo - Índice de S. Roque - teria sido escrito no primeiro decênio do séc. XVIII, e o segundo Index Domus Professae -, por volta de 1740. Nós conseguimos localizar só o primeiro deles: Índice da Biblioteca do Colégio de São Roque, Ms. 51-XI-37, mas não o utilizamos na realização deste estudo; ver: PEREIRA GOMES, J. As antigas livrarias dos Jesuítas em Lisboa. Brotéria, v.XL, fasc.2, Lisboa, p.153-161, 1945.
} 
fonte para conhecimento, por parte dos modernos, da arte e da técnica dos antigos.

A primeira delas é a Naturalis Historia de Plínio, o Velho (c. 23-79 d.C.). Compilação enciclopédica que foi a principal fonte sobre a arte antiga de que dispuseram os homens do Renascimento, uma vez que nenhum dos tratados dos autores gregos por ele citados foi transmitido à modernidade.

Nos quatro capítulos em que trata de questões histórico-artísticas - 0 XXXIV, aeris metalla, sobre a bronzística; o XXXV, honos picturae, sobre a pintura; o naturae lapidistica, sobre a marmoraria e o XXXIII, metallorum naturae, sobre a ourivesaria ${ }^{7}$-, a obra traz informações biográficas acerca dos artistas gregos e constrói um quadro do desenvolvimento progressivo da arte antiga que muito influenciaria os escritos de autores do Renascimento italiano, de Ghiberti a Vasari. ${ }^{8}$ Amplamente difundido em Portugal, ${ }^{9}$ o livro de Plínio consta dos dois catálogos aqui estudados.

A lista de livros de Santo Antão aqui examinada cataloga os autores presentes na biblioteca do colégio dividindo-os entre os seguintes grupos: Santos Padres e Intérpretes, Teólogos, Direito civil e canônico (luris Utriusque), Pregadores (Concionatores), Filósofos, Matemáticos, Humanistas, Historiadores e Ascetas. Plínio é classificado, juntamente com Cícero e Ovídio, entre os "Humanistas", não entre os "Historiadores".

A segunda obra clássica de forte interesse histórico-antiquário que encontramos é a Descrição da Grécia (Hellàdos Perieghésis) de Pausânias (c. 143-175 d.C.). Dela localizamos um único volume bilíngue - greco-latino - na biblioteca do Colégio de São Roque.

Tendo conhecido muitas edições ao longo do século XVI ${ }^{10}$ e algumas ao longo dos dois séculos sucessivos, a obra de Pausânias ofereceu aos modernos um itinerário histórico-geográfico dos lugares e dos monumentos da Grécia antiga, fornecendo uma rica descrição da arquitetura dos templos e das obras de arte (pinturas e esculturas) que neles se encontravam. ${ }^{11}$

Concebido sob a forma do gênero tipicamente helenístico da periégese, a Descrição da Grécia foi certamente um relevante modelo para a vasta literatura de viagem e para as numerosas obras de topografia artística produzidas na Europa Moderna, de que trataremos a seguir.

7 HARARI, Maurício. Plinio il vecchio e la storia dell'Arte Antica. In: FERRI, Silvio (a cura di). Storia delle Arti Antiche. Milano: BUR, 2000.

8 Ver: BECATTI, Giovanni. Plinio e Vasari. In: Kosmos, studi sul mondo classico. Roma: L'Erma di Bretschneider, 1987, p.629-640.

9 Sobre a recepção de Plínio em Portugal, ver: Os clássicos no tempo: Plínio, o velho, e o Humanismo português (Actas do Colóquio Internacional, Lisboa, 31 mar. 2006). Lisboa: Centro de Estudos Clássicos, 2007. Para a ampla fortuna de Plínio na Europa Moderna, ver: NAUERT JR., Charles G. Caius Plinius secundus. In: Catalogus Translationum et Commentariorum: mediaeval and renaissance latin translations and commentaries. v.IV. Washington D. C.: The Catholic University of America Press, 1980, p.297-422.

10 Para fortuna de Pausânias no século XVI, ver: PARKS, George B. Pausanias. In: Catalogus Translationum et Commentariorum: mediaeval and renaissance latin translations and commentaries. v.II. Washington D. C.: The Catholic University of America Press, 1971. p.215-220.

11 ARAFAT, K.W. Pausanias' Greece: ancient artists and Roman rulers. Cambridge: Cambridge University Press, 1996. 
Infelizmente, não havendo um volume da obra na biblioteca do Colégio de Santo Antão, não podemos saber em que grupo seu autor seria classificado, se entre os "Humanistas", como Plínio, se entre os "Historiadores", como Heródoto, ou se entre os "Matemáticos", como outros geógrafos antigos, tais como Ptolomeu e Pompônio Mela. É nessa última categoria que encontramos os outros dois autores antigos de que aqui trataremos: Vitrúvio e Euclides.

Os Dez Livros sobre Arquitetura do arquiteto romano Vitrúvio Polião (séc. I d.C.) são o único tratado de arquitetura da Antiguidade transmitido à modernidade, assim como a única literatura artística escrita por um "artista profissional" que a tradição clássica legou à posteridade. ${ }^{12}$

Principal fonte para o conhecimento dos materiais e dos métodos construtivos dos romanos, suas tipologias edilícias e sua concepção de arquitetura, o De Architectura foi o fundamento sobre o qual se construiu o edifício teórico da arquitetura do Renascimento ao menos até o século XIX.13 Sendo de particular relevância para as formulações dos modernos sua teoria sobre as ordens arquitetônicas e suas considerações sobre a scaenographia ${ }^{14}$ - termo que designa um dos métodos de desenho arquitetônico que os exegetas renascentistas traduziram quase unanimemente pelo termo perspectiva. ${ }^{15}$

É também através da questão da perspectiva como técnica de representação e da importância dos conhecimentos de geometria, ótica e catróptica para formulação da prospectiva pingendi do Renascimento que justificamos a inclusão da obra de Euclides como "literatura artística".

A perspectiva naturalis de Euclides, ou seja, sua formulação geométrica da teoria da visão da escola pitagórica, consistiu em importantíssima base teórica para os estudos da projeção da luz, da teoria das proporções e da "arte de medir com a vista" de que dispuseram os modernos. Tais conhecimentos, ainda que indiretamente, permitiriam a elaboração daquilo que os codificadores do século XVI chamariam de "la prima regola prospettica" ${ }^{16}$

Inúmeras vezes editada ao longo da Idade Moderna, a obra euclidiana esteve no cerne da educação matemática europeia dos séculos XVI, XVII e $\mathrm{XVIII}$. Encontrados nas duas bibliotecas lisboetas, os Elementos foram o eixo central de vários cursos ministrados nos colégios jesuíticos em Portugal. ${ }^{17}$

12 Encontramos volumes da obra vitruviana em ambas as bibliotecas

13 Sobre a fortuna e a importância da obra de Vitrúvio da Idade Média ao século XVIII, ver: KRUFT, Hanno-Walter. Storia delle teorie archittetoniche: da Vitruvio al Settecento. Roma/Bari: Laterza, 1999.

14 Ver VITORINO, Julio César. A scaenographia vitruviana e a perspectiva artificialis. In: MELLO, Magno Moraes (org.). Ars, techné, technica: a fundamentação teórica e cultural da perspectiva. Belo Horizonte: Argumentum, 2009, p.91-100.

15 CAMEROTA, Filippo. La prospettiva del Rinascimento: arte, architettura, scienza. Milano: Mondadori Electa spa. 2006, p.45.

16 CAMEROTA, Filippo. La prospettiva del Rinascimento, p.45.

17 Em 1735, o padre jesuíta Manoel de Campos publicava uma edição dos Elementos "Para Uso da Real Aula Da Esfera do Collegio de Santo Antão": Elementos De Geometria Plana, e Solida, Segundo A Ordem de Euclides, Príncipe Dos Geometras. Accrescentados Com Tres Uteis Appendices: o primeiro da Logistica das Proporções: 0 segundo dos Theoremas selectos de Archimedes: o terceiro da Quadratiz de Dinostrato, para quadrar o Circulo, e tri-seçar o Angulo... Offerecidos A' Magestade D'El Rey Nosso Senhor D. João V. Lisboa Occidental: na Officina Rita-Cassiana, 1735. 


\section{Tratados sobre o culto das imagens}

Apesar da discussão acerca da representação das imagens sacras não dizer respeito diretamente ao domínio do fazer artístico, ela é extremamente relevante para a compreensão da função espiritual e social das imagens de cunho devocional, sobretudo a partir do século XVI, quando a ameaça da Reforma suscita novas exigências à representação artística. ${ }^{18}$

No contexto da terceira sessão do Concílio de Trento (1562-1563), foi publicada uma série de decretos sobre as letras e as artes que vieram ao encontro dessa necessidade de repensar o papel e os usos da arte sacra, assim como delimitar o representável, isto é, definir uma nova concepção de decoro (decorum). ${ }^{19}$

Na biblioteca do Colégio de São Roque encontramos três dos mais significativos textos sobre essa reflexão escritos ao longo da segunda metade do século XVI: o capítulo do De Controversiis Christianae ${ }^{20}$ de Roberto Bellarmino, dedicado a De reliquiis et imaginibus sanctorum; ${ }^{21}$ o De picturis et imaginibus sacris, ${ }^{22}$ de Johannes Molanus - primeiro comentário aos decretos tridentinos sobre o uso de imagens religiosas a partir de uma reflexão sobre a nudez na arte ${ }^{23}$ - e a versão latina ${ }^{24}$ do Discorso intorno alle imagini sacre e profane ${ }^{25}$ do cardeal bolonhês Gabriele Paleotti.

\section{A Topografia Artística}

Estas espécies de guias de uma cidade ou região, tipo de escrito derivado da literatura periegética antiga e dos livros destinados aos peregrinos medievais, se proliferaram na Europa ao longo do século XVI.

18 GROULIER, Jean-François. A teologia da imagem e o estatuto da pintura. In: LICHTENSTEIN, Jacqueline. (dir.). A pintura: textos essenciais. v.2 . São Paulo: Editora 34, 2004, p.9-15.

19 Ver DEJOB, Charles. De l'influence du Concile de Trente sur la littérature et les beaux-arts chez les peuples catholiques. Paris: E. Thorin, 1884; MÂLE, Emile. L'art religieux aprés le Concile de Trente: étude sur l'iconographie de la fin du XVleme, du XVIleme et du XVIlleme siècles en Italie, en France, en Espagne et en Flandre. Paris: Colin, 1932; BLUNT, Anthony. O Concílio de Trento e a Arte Religiosa. In: Teoria artística na Itália, 1450-1600. São Paulo: Cosac \& Naify, 2001; PRODI, Paolo. Ricerche sulla teorica delle arti figurative nella riforma. In: Archivio italiano per la storia della pietà. v.IV. 1965, p.121-212; SCAVIZZI, Giuseppe. The controversy on images: from Calvin to Baronius. New York: Peter Lang, 1992.

20 Disputationes de Controversiis Christianae Fidei adversus hujus temporis hereticos..., impressas pela primeira vez, em três volumes, em Ingolstadt entre 1586-89.

21 Ver DAURENTIIS, Valeria. Immagini ed arte in Bellarmino. In: Bellarmino e la Controriforma. (Atti del Simposio Internazionale di Studi, Sora 15 - 18 out.1986). Sora: Centro di Studi Vicenzo Patriarca, 1990, p.579-608.

22 Pelo título transcrito no catálogo de Santo Antão, o volume conservado na biblioteca correspondia à primeira edição da obra: De Picturis et Imaginibus Sacris, Liber unus, tractans de vitandis circa eas abusibus ac de earundem ignijicationibus, Louvain, 1570, uma vez que em suas sucessivas edições a obra foi publicada com o título De Historia Sanctarum Imaginum et Picturarum.

23 FREEDBERG, David. Johannes Molanus on provocative paintings: de historia sanctarum imaginum et picturarum, book II, Chapter 42. Journal of the Warburg and Courtauld Institutes, n.34, p.229-245, 1971.

24 De imaginibus sacris et profanis (...), tradução do texto italiano publicada pela primeira vez em Ingolstadt em 1594.

25 Editio princeps: Discorso intorno alle imagini sacre e profane. Diviso in cinque libri, dove si scuoprono varii abusi loro e si dichiara il vero modo che cristianamente si doveria osservare nel porle nelle chiese, case et in ogni altro luogo. Raccolto e posto insieme ad utile delle anime per commissione di Monsignore Illustriss. e Reverendiss. Card. Paleotti Vescovo di Bologna. Al popolo della città e diocese sua. In Bologna, per Alessandro Benacci, MDLXXXI. 
A grande maioria desses escritos, tais como tinham sido os Mirabilia medievais, era dedicado à cidade de Roma. ${ }^{26}$ Nesse momento o interesse dos viajantes pelo caput mundi era mais vivo do que nunca: o culto aos monumentos antigos que caracterizou o Renascimento e os programas papais de renovação arquitetônica e urbanística da cidade somaram-se ao já consolidado interesse de cunho religioso.

Na biblioteca de Santo Antão encontramos um exemplar do Roma instaurata de Flavio Biondo..$^{27}$ Inspirado nas Antiquitates de Varrão, ou melhor, naquilo que foi escrito por Santo Agostinho sobre elas, o livro - dedicado ao papa Eugenio IV - faz uma reconstrução histórica da topografia romana antiga a partir dos restos ainda visíveis: nele o autor descreve monumentos e ruínas da Roma pagã e fornece informações sobre a Roma cristã e seus lugares sagrados. ${ }^{28}$

Na mesma biblioteca, encontramos o Antiquae urbis splendor do pintor e gravador italiano Giacomo Lauro. Publicada em quatro partes entre 1612 e $1628,{ }^{29}$ a obra é ricamente ilustrada, com um total de 167 gravuras que representam todos os mais importantes monumentos arquitetônicos da cidade, incluindo - no quarto volume - as grandes basílicas, palácios e villas construídos em época moderna.

Já na biblioteca de Santo Antão o que encontramos são duas reelaborações de Le cose meravigliose dell'alma città di Roma: guia publicado pela primeira vez em Veneza em 1541, cujo núcleo original seria submetido a inúmeras modificações e adições no contexto das muitas edições que dele viriam à luz no decorrer da Idade Moderna.

A primeira delas é um exemplar da edição de Le cose meravigliose impressa e ilustrada por Girolamo Franzini (publicada em Veneza em 1588, reimpressa em Veneza em 1594 e em Roma em 1595). Essa versão, que incorpora no texto Le Antichità di Roma de Andrea Palladio (Roma e Veneza, 1544), ${ }^{30}$ contém pela primeira vez as xilogravuras de Franzini, as quais são de grande relevância, uma vez que serão reutilizadas por mais de um século na ilustração dos guias sobre a cidade de Roma. ${ }^{31}$

Os herdeiros de Girolamo, nos anos sucessivos, viriam a estampar não somente outras versões italianas do guia - como aquela redigida pelo romano Prospero Parisi -, mas também três versões do mesmo em língua

26 Ver: SCHUDT, Ludwig. Le guide di Roma: materialen zu einer geschichte der römischen topographie. Wien/Augsburg: Filser, 1930.

27 Ver: FUBINI, Riccardo. Flavio Biondo. In: Dizionario Biografico degli Italiani. v.X, Roma: Treccani, 1968, p.536-559

28 Do mesmo autor, encontramos na Biblioteca de São Roque a versão em língua vulgar do Roma Triumphante dedicado às instituições romanas - feita por Lucio Fauno pela prensa de Michele Tramezzino.

29 À primeira edição seguiram-se várias. Ver: DI CALISTO, Laura. Giacomo Lauro. In: Dizionario Biografico degli Italiani. v.64. Roma: Treccani, 2005

30 Composta por 31 folhas in $8^{\circ}$ sem ilustrações. Ver: DAVIS, Margaret Daly. Dietro le quinte dell'Antichità di Roma di M. Andrea Palladio raccolta brevemente da gli auttori antichi, et moderni: quanto Palladio. In: Palladio: 1508-2008. Venezia: Marsilio, 2008, p.196-198.

31 Ver: BRACH, Carla Casetti. Girolamo Franzini. In: Dizionario Biografico degli Italiani. v.50, Roma: Treccani, 1998. 
castelhana ${ }^{32}$ : uma primeira de $1589,{ }^{33}$ uma segunda de 1600 e uma terceira, que teve duas edições, em 1610 e em 1619, atribuída a Pietro Martire Felini e intitulada Tratado nuevo de las cosas maravillosas de la Alma ciudad de Roma.

É a segunda dessas versões, a de 1600, intitulada Las iglesias de Roma, etc. ${ }^{34}$ e atribuída a Francisco Cabrera Morales, que encontramos no catálogo de São Roque. Apesar de no título não haver mais qualquer imediata referência ao texto original, trata-se sempre de uma tradução de Le cose meravigliose com ilustrações de Franzini. De autoria de Cabrera Morales são, sobretudo, as interpolações de trechos do texto de Palladio e atualizações dos textos com a inserção de notícias sobre edifícios modernos como o obelisco de São Pedro e a Capela Sistina.

Todavia, não só à Roma foram dedicadas topografias artísticas. Outras cidades e regiões também foram descritas em obras de cunho periegético. Na biblioteca de São Roque, por exemplo, encontramos um tomo da Descripção de Veneza de Francisco Sansovino. ${ }^{35}$ Nela é feita uma reconstrução topográfica de cada bairro (sestiere) citadino, com suas igrejas e obras de arte. Apesar da ausência de qualquer aparato de imagens, são particularmente ricos de informações artísticas os Livros VII e IX, o primeiro dedicado à descrição das sedes das confrarias venezianas (scuole), o segundo, à descrição dos palácios públicos e privados. ${ }^{36}$

Nas duas bibliotecas lisboetas encontramos também a Descrição dos Países Baixos de Lodovico Guicciardini. ${ }^{37}$ Uma descrição geopolítica da região, dedicada a Felipe II de Espanha, que inclui significativas informações sobre seus artistas. Principal fonte de informação sobre os artistas flamengos do século XVI, segundo Dina Aristodemo ${ }^{38}$ teria sido utilizada por Vasari na preparação da segunda edição de suas Vidas. ${ }^{39}$

32 CÁMARA, Alicia. Peregrinar con guia en el Siglo de Oro. In: SÁNCHEZ, Carlos José Hernando (coord.). Roma y España: un crisol de la cultura europea en la Edad Moderna (Actas del Congreso Internacional celebrado en la Real Academia de España en Roma del 8 al 12 de mayo de 2007). v.ll. Madrid: Sociedad Estatal para la Acción Cultural Exterior, 2007, p.767-779.

33 Las cosas maravillosas de la Santa Ciudad de Roma... en Roma, por Hieronymo Francino librero... MDLXXXIX.

34 Las iglesias de Roma con todas las relíquias y estaciones... en Roma por Luis Zanetti, a instancia de Gio. Antonio Franzini. Año 1600.

35 Venetia città nobilíssima et singolare descritta (Editio princeps: Veneza, 1581).

36 SCHLOSSER, Magnino. La letteratura artística, p.367.

37 Descrittione di tutti i Paesi Bassi, altrimenti detti Germania inferiore. Con più carte di geographia del paese et col ritratto naturale di più terre principali (Editio princeps: Anversa: 1567).

38 ARISTODEMO, Dina. Lodovico Guicciardini e la 'descrittione di tutti i Paesi Bassi. Studi e problemi di critica testuale, n.16, p.217-224, abr. 1978.

39 É interessante notar que na divisão do índice de autores da biblioteca de Santo Antão, enquanto Biondo foi colocado entre os "Humanistas", Lauro e Guicciardini encontravam-se entre os "Matemáticos", classificação genérica que incluía aqueles autores que hoje chamaríamos de "geógrafos". Lauro, de fato, nos anos de 1630-1645 se dedicou à publicação de uma série de mapas e descrições de cidades na forma de pequenos opúsculos - alguns dos quais foram reunidos em 1639 sob o título de Heroico splendore delle città del mondo. 


\section{Biografias de Artistas e Tratados sobre Pintura}

Não encontramos em nenhuma das listas estudadas referências a "biografias de artistas" ou a "tratados sobre pintura", apesar de ambos os gêneros terem sido profusamente produzidos entre o fim do século XVI e o início do século XVIII.

Apesar de Sebastiano Serlio - de quem nos ocuparemos em seguida - tratar de pintura parietal em um Apêndice do Livro IV de seu Tratado de Arquitetura, não encontramos nas bibliotecas estudadas nenhuma obra que tratasse especificamente de pintura como o De Pictura de Alberti, ${ }^{40}$ o Trattato dell'arte de la pittura de Lomazzo ou El museo pictorico y escala optica de Palomino.

Não encontramos nem mesmo tratados impressos em Portugal como a Arte da Pintura ${ }^{41}$ de Filipe Nunes - publicado em Lisboa, por Pedro Crasbeeck, em 1615 - ou os Artefactos symmetriacos ${ }^{42}$ do padre Ignacio da Piedade Vasconcellos - publicado em Lisboa, na Officina de Joseph Antonio da Sylva, em 1733.

$\mathrm{O}$ único texto sobre pintura escrito por um português que pudemos identificar entre os livros dessas bibliotecas foi o capítulo "Príncipios, e Progresso da Escultura e Pintura" da obra Eva, e Ave (1676) do diplomata Antonio de Sousa de Macedo, que constava nas prateleiras da Biblioteca do Colégio de Santo Antão. ${ }^{43}$

\section{Tratados de Arquitetura}

É na biblioteca do Colégio de São Roque que esses tratados são encontrados em grande número. Nela encontramos os tratados de Alberti, Serlio, Labacco, Cataneo, Vignola, Maggi e Fortes.

O De re ædificatoria libri decem de Leon Battista Alberti - em princípio um comentário ao texto vitruviano, depois um tratado escrito em latim concluído em 1452 - teve sua primeira impressão em Florença no ano de 1485. Sua primeira edição em língua vulgar, que também foi a primeira versão ilustrada do texto, foi preparada por Cosimo Bartoli, em 1550.

Segundo Kruft, o tratado de Alberti, por não ser ilustrado e por ter um caráter mais teórico do que prático, não teria tido, ao longo da Idade Mo-

40 O livro de Alberti foi, juntamente com a Noticia general para la estimación de las artes (1600) de Gaspar Gutièrrez de los Rios, o Ideia dos Pintores, Escultores e Arquitetos (1607) de Federico Zuccaro e o Diálogos de la Pintura (1633) de Vincente Carducho, utilizado como fonte por Félix da Costa em seu tratado que, escrito em 1696, permaneceu inédito até a segunda metade do século XX. COSTA, Félix. The antiquity of the art of painting. New Haven: Yale University Press, 1967; ver: SOBRAL, Luís de Moura. Do sentido das imagens: ensaios sobre pintura barroca portuguesa e outros temas ibéricos. Lisboa: Estampa, 1996, p.160.

41 Arte poetica e da pintura, e symmetria, com principios da perspectiva.

42 Artefactos symmetriacos, e geometricos, advertidos, e descobertos pela industriosa perfeição das artes, esculturaria, architectonica, e da pintura.

43 Eva, e Ave ou Maria triumphante theatro da erudiçam, e da Philosophia chrystam: em que se representam os dous estados do mundo: cahido em Eva, e levantado em Ave... escrevia Antonio de Sousa de Macedo: primeira, e segunda parte. Lisboa: à despesa de Antonio Craesbeeck de Mello, impressor da Casa Real, 1676. 
derna, a mesma penetração e difusão que os tratados de Vitrúvio, Serlio e Vignola. ${ }^{44} \mathrm{Na}$ biblioteca de São Roque, todavia, havia dois volumes do tratado, um em espanhol, outro em florentino, este último, possivelmente, a versão ilustrada de Bartoli ou uma de suas reimpressões.

Do tratado de Sebastiano Serlio, a biblioteca tinha 3 volumes; esses continham quatro dos sete livros do autor publicados durante o século XVI45: o Livro IV, Regole generali della architettura; ${ }^{46}$ o Terzo libro, nel quale si figurano e si descrivono le antiquità di Roma ${ }^{47}$ e o Il primo ed il secondo libro d'Architettura. ${ }^{48}$

Em Portugal, como no resto da Europa, o livro de Serlio foi bastante conhecido. Todavia, apesar de sua linguagem clara e simples, segundo Serrão, não foi replicado em seu aspecto doutrinário, mas sim por seu aparato de gravuras, utilizado como fonte inspiradora para o desenho de portadas, de capitéis, de entablamentos, etc. ${ }^{49}$

L'Architettura de Pietro Cataneo ${ }^{50}$ foi também muito difundido ao longo do século XVII. O tratado, de dimensões análogas ao de Serlio, se ocupa de arquitetura militar, eclesiástica e civil. Sua relevância está atrelada a alguns posicionamentos do autor, sobretudo no Livro I, em que, de forma pioneira, considera a projetação da cidade como o principal escopo da arquitetura, e no Livro III, dedicado à construção de igrejas, em que - opondo-se abertamente a Serlio, que em seu Livro V sobre a mesma temática defendia os edifícios de planta central - se pronuncia a favor da planta em cruz latina. ${ }^{51}$

O texto já era conhecido em Portugal na segunda metade do século XVI, uma vez que figura, juntamente com Serlio e Vitrúvio, entre as fontes utilizadas no tratado de arquitetura ${ }^{52}$ atribuído por Rafael Moreira ao português Antonio Rodrigues (c.1520-1590), arquiteto e lente da Aula de Arquitetura do Paço da Ribeira. ${ }^{53}$

Já o livro de Antonio Labacco, Libro appartenente a l'architettura nel qual si figurano alcune notabili antiquità di Roma - publicado pela primeira vez em Roma, em 1552 - era bem menos difundido. Seguindo a mesma linha do Livro III do Tratado de Serlio, ele se propõe ao estudo da estrutura arqui-

44 KRUFT, Hanno-Walter. Storia delle teorie archittetoniche, p.35.

$45 \mathrm{O}$ Livro VI e o VIII foram publicados somente no século XX.

46 Dedicado às ordens arquitetônicas, foi o primeiro a ser publicado (Editio princeps: Veneza, 1537).

47 Editio princeps: Veneza, 1540.

48 Editio princeps: Paris, 1545.

49 SERRÃO, Victor. História da Arte em Portugal: o Renascimento e o Maneirismo (1500-1620). Lisboa: Editorial Presença, 2001, p.53.

50 Publicado pela primeira vez com esse título, em Veneza, em 1567. A Editio princeps (Veneza, 1554) era intitulada I quattro primi libri di architettura, etc..

51 KRUFT, Hanno-Walter. Storia delle teorie archittetoniche, p.85-88.

52 Do qual chegaram até nós duas versões manuscritas: uma versão preliminar, conservada na Biblioteca Nacional de Lisboa (Cód.3675), e outra, conservada na Biblioteca Pública Municipal do Porto com o título "Proposições Matemáticas" (Ms.95).

53 Ver: MOREIRA, Rafael. Um tratado português de arquitectura do século XVI (1576-1579). Lisboa: Universidade Nova de Lisboa, 1982 (História da Arte, Dissertação de mestrado). 
tetônica dos edifícios da Roma antiga e faz uma reconstrução desses monumentos através da elaboração de uma vasta série de tábuas ilustrativas.

O Regole delle cinque ordine dell'Architettura de Vignola não é exatamente um tratado, na medida em que nele o texto escrito fica em segundo plano em relação às tábuas gravadas. Exceto uma breve introdução, a obra consiste no comentário das gravuras impressas. Segundo Kruft, foi o texto arquitetônico mais editado e mais utilizado até o século XIX, servindo de base para o ensino nas escolas de arquitetura. ${ }^{54}$ Esse, talvez, seja o motivo dele ser o único Tratado de Arquitetura moderno entre livros de "Matemáticos" na biblioteca do Colégio de Santo Antão.

O tratado Della fortificatione delle città de Girolamo Maggi e lacopo Fusti Castriotto - publicado em Veneza, em 1564 -, por sua vez, representa uma tentativa de inserir a arquitetura militar num contexto humanístico. O corpo central do tratado é substancialmente obra do engenheiro militar Castriotto; enquanto Maggi, de formação humanística, é responsável pela introdução e pelos comentários que conferem ao texto riqueza de citações e excursus históricos. ${ }^{55}$

Dedicado também exclusivamente à arquitetura militar é o Engenheiro portuguez de Manuel Azevedo Fortes ${ }^{56}$ - publicado em Lisboa, em dois volumes, um de 1728, outro de 1729. Entretanto, se no livro de Maggi e Castriotto o estudo sobre as fortificações vem precedido por uma reflexão acerca de questões gerais de urbanismo, o livro de Fortes dedica a primeira parte de seu texto a conceitos geométricos e trigonométricos.

A obra de Fortes é o único Tratado de Arquitetura publicado em Portugal que encontramos nessas bibliotecas. Particularmente notável é a ausência de Medidas do Romano de Diego Sagredo, publicado em Lisboa com grande tiragem em 1541 e 1542, e do Methodo Lusitano de Luis Serrão Pimentel, publicado em Lisboa por Antonio Craesbeeck de Mello em 1680.

Significativa, também, tratando-se de bibliotecas de uma ordem religiosa, é a ausência de tratados mais diretamente relacionados ao movimento da Contrarreforma, como as Instructiones de Carlo Borromeo.

\section{Tratados sobre Perspectiva}

O já mencionado Livro II do tratado de Serlio trata da perspectiva com um e com dois pontos de fuga. ${ }^{57}$ Nele o autor expõe considerações sobre a interdependência entre pintura, perspectiva e arquitetura. ${ }^{58}$

\footnotetext{
54 KRUFT, Hanno-Walter. Storia delle teorie archittetoniche, p.90.

55 KRUFT, Hanno-Walter. Storia delle teorie archittetoniche, p.134.

56 Ver: FERNANDES, Mário Gonçalves. (org.). Manoel de Azevedo Fortes (1660-1749): cartografia, cultura e urbanismo. Porto: GEDES, 2006

57 LEITÃO, Henrique; MELLO, Magno. A pintura barroca e a cultura matemática dos Jesuítas, p.99.

58 Ver CAMEROTA, Filippo. La prospettiva del Rinascimento, p.139-146
} 
Na biblioteca de São Roque também encontramos uma edição do Le due regole della prospettiva de Vignola, publicado em 1583, até então a exposição mais completa feita sobre os métodos perspécticos. A primeira regra ocupa oito capítulos e a segunda, vinte e um, sendo todo o texto dedicado ao pintor-desenhador. ${ }^{59}$

Também estão presentes nas bibliotecas lisboetas inúmeros tratados matemáticos que versam sobre perspectiva. Esses porém não são voltados para o fazer artístico como os textos de Serlio e de Vignola, sendo dedicados mais à perspectiva naturalis do que à perspectiva pingendi.

Dentre eles destacamos o Cursus Seu Mundus Mathematicus de Claude Dechales publicado em Paris em $1690^{60}$ e o Opticorum libri sex philosophis juxta ac mathematicis utiles do jesuíta François Aguilon, publicado em Antuérpia em 1613 e ilustrado por gravuras encomendadas a Peter Paul Rubens, ambos presentes na biblioteca de Santo Antão.

Não encontramos, entretanto, dois outros importantes tratados sobre perspectiva pingendi escritos por jesuítas ao longo do século XVII: La perspectiva pratique de Pe. Jean Dubreuil e o Perspectiva Pictorum et Architectorum de Pe. Andrea Pozzo.

O livro de Pozzo era certamente conhecido em Portugal no início do século XVIII; prova disto é a sua utilização pelo jesuíta português Inácio Vieira na preparação de seu Tractado de Prospectiva, ${ }^{61}$ escrito em torno de 1715 e inédito até os dias de hoje.

Além de Pozzo, são fontes de Vieira vários dos textos que encontramos nas bibliotecas dos colégios de Lisboa - Vitrúvio, Serlio, Vignola, Cataneo, Dechales -, assim como outros autores que nelas não foram encontrados, como Palladio, Barbaro, Scamozzi, Frei São Nicolau etc. ${ }^{62}$ Pertenceriam essas obras à sua biblioteca pessoal?

De um modo mais genérico, isso nos coloca um questionamento sobre o processo e o período de formação dessas bibliotecas, uma vez que os autores estrangeiros dos séculos XVI são bem mais presentes que a literatura artística produzida na Europa como um todo nos séculos XVII e XVIII.

Por outro lado, nota-se a ausência das inúmeras publicações feitas em terras portuguesas ao longo desses mesmos séculos. Nesse sentido, o estudo dessas bibliotecas coloca em questão o paradigma "nacionalista" que caracteriza a história do livro em Portugal, predominantemente concentrada sobre a produção de textos publicados em terras lusas. Pelo menos no que diz respeito à literatura artística, nossas bibliotecas apontam para

59 LEITÃO, Henrique; MELLO, Magno. A pintura barroca e a cultura matemática dos Jesuítas, p.97. Ver: CAMEROTA, Filippo. La prospettiva del Rinascimento, p.160-175.

60 LEITÃO, Henrique; MELLO, Magno. A pintura barroca e a cultura matemática dos Jesuítas, p.122-123.

61 Biblioteca Nacional de Lisboa. Cód. 5170.

62 LEITÃO, Henrique; MELLO, Magno. A pintura barroca e a cultura matemática dos Jesuítas, p.120-121. 
uma grande presença de obras impressas em outros países. É sobretudo a partir delas que circulava e se produzia o conhecimento.

O fato de a maioria dos tratados de arte portugueses da Idade Moderna terem permanecido inéditos, ${ }^{63}$ assim como a pouca circulação fora do espaço luso dos autores portugueses que tiveram suas obras impressas, parece confirmar a percepção de que o Portugal moderno foi mais um lugar de recepção do que de produção de ideias artísticas.

Entretanto, somente uma análise aprofundada dos tratados portugueses - impressos ou manuscritos - voltada a determinar o "grau de inovação" neles contido poderia fornecer uma resposta mais exata a essa questão. Do mesmo modo, só assim poderíamos saber de fato quais dos autores disponíveis para leitura foram utilizados e quais conteúdos de seus tratados tiveram maior impacto, quais menos ou nenhum.

Parece-nos, porém, poder afirmar desde já que a produção de tratados em solo luso, em grande medida, reproduziria o mesmo predominante interesse teórico pela arquitetura, em detrimento da reflexão sobre os demais fazeres artísticos, que encontramos expresso na seleção dos livros das duas bibliotecas aqui estudadas.

Aparentemente, confirmam-se as palavras de Luís de Moura Sobral:

Contrariamente ao que se passa com outras manifestações, com a poesia e com a literatura de ficção, por exemplo, nunca em Portugal se reconheceu à pintura, à escultura ou à arquitetura a importância que de uma maneira ou outra, elas de facto tiveram na dinâmica da vida cultural. ${ }^{64}$

O cariz mecânico a que continuou associada a prática artística em Portugal não favoreceu a elaboração de uma expressão teórica de vulto à altura da riqueza inventiva que teve a produção arquitetônico-artística no mundo luso no mesmo período.

63 É o caso do já citado Antiguidade da Arte da Pintura (1696) de Félix da Costa, do Elogio da Pintura (1687) de Luís Nunes Tinoco, do Pintura e Poesia, Poesia e Pintura (1633) de Manuel Pires de Almeida, entre outros.

64 SOBRAL, Luís de Moura. Do sentido das imagens, p.159. 